\title{
Ethnopharmacological survey of medicinal plants in Jeju Island, Korea
}

\author{
Mi-Jang Song ${ }^{1}$, Hyun Kim ${ }^{1 *}$, Brian Heldenbrand ${ }^{2}$, Jongwook Jeon ${ }^{3}$ and Sanghun Lee ${ }^{3}$
}

\begin{abstract}
Background: This study aims to analyze and record orally transmitted knowledge of medicinal plants from the indigenous people living in Hallasan National Park of Korea.

Methods: Data was collected through the participatory rural appraisal method involving interviews, informal meetings, open and group discussions, and overt observations with semi-structured questionnaires.

Results: In this study, a total of 68 families, 141 genera, and 171 species of plants that showed 777 ways of usage were recorded. Looking into the distribution of the families, 14 species of Asteraceae occupied $11.1 \%$ of the total followed by 13 species of Rosaceae, 10 species of Rutaceae, and nine species of Apiaceae which occupied 5.0\%, $7.1 \%$ and $3.0 \%$ of the whole, respectively. 32 kinds of plant-parts were used for 47 various medicinal purposes. Values for the informant consensus factor regarding the ailment categories were for birth related disorders (0.92), followed by respiratory system disorders (0.90), skin disease and disorders (0.89), genitourinary system disorders (0.87), physical pain (0.87), and other conditions. According to fidelity levels, 36 plant species resulted in fidelity levels of $100 \%$.
\end{abstract}

Conclusion: Consequently, results of this study will legally utilize to provide preparatory measures against the Nagoya Protocol (2010) about benefit-sharing for traditional knowledge of genetic resources.

Keywords: Traditional Knowledge, Participatory rural appraisal, Informant consensus factor, Fidelity level, Hallasan National Park

\section{Introduction}

Hallasan National Park, which possesses a wonderful ecological geography and a unique traditional culture, was designated as a Biosphere Reserve in 2002, a World Natural Heritage in 2007, and a Global Geopark in 2010, making the sub-tropical island the only place on Earth to receive all three United Nations Educational, Scientific and Cultural Organization (UNESCO) designations in the field of natural science.

Mt. Halla $(1,950 \mathrm{~m})$ is located at the center of the Hallasan National Park as a volcanic island distributed randomly over 360 parasitic volcanos ("oreums" in Korean). Hallasan National Park is separated by the Jeju Channel, $59 \mathrm{~km}$ in width, across from Haenamgot, which is the southernmost tip of the Korean Peninsula and is made up of eight inhabited isles and 54

\footnotetext{
* Correspondence: hyunk@jj.ac.kr

${ }^{1}$ School of Alternative Medicine and Health Science, Jeonju University, 303 Cheonjam-ro, Wansan-gu, Jeonju 560-759, Republic of Korea

Full list of author information is available at the end of the article
}

uninhabited islets. Particularly, Hallasan National Park lies in the middle of the triangle which consists of the Korean Peninsula, the Japanese islands and the Chinese continent. The nearest point to Japan from Jeju Island is the city of Sasebo $(250 \mathrm{~km})$; and for China, it is the mouth of the Yangtze River in the Shanghai area. Therefore, this ideal location has been advantageous for exchanging cultures and goods within these regions. Hallasan National Park has been referred to as a small continent in far east Asia due to its unique culture that the people of Jeju have created.

Traditionally, Jeju is famous for its abundance of three items, which include Seokda (rocks), Pungda (wind), and Yeoda (women). Seokda originated from the past volcanic activity of Mt. Halla. The inhabitants of Jeju Island needed to cultivate the land through a long process of clearing away the numerous rocks covering the land and then form inlets for irrigation, and finally construct walls for protection against the wind. The abundance of

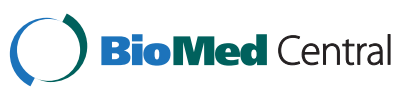


Seokda speaks of the harsh surroundings on Jeju Island. The island is located in the path of typhoons; therefore, the islanders have had to fight against the sea. The effects of Pungda and Seokda impact the lifestyle of the inhabitants on Jeju Island. Two examples are the thatched roofs which are tied up with straw rope, and the fields surrounded by stone walls. The third element which exists on Jeju Island isYeoda, which originated from the fact that most men on the island were lost at sea, and therefore caused the women to outnumber the men. Also, women had to come out into the fields with men due to the Jeju Island's harsh living environment. The abundance of Yeoda is a stated comment on population statistics, but moreover it is a metaphor for women living on Jeju Island who work diligently. The famous women-divers on the island ("haenyo" in Korean), who fight against the wild waves to catch fish are very symbolic to Jeju Island.

The agriculture of Jeju Island has traditionally been famous for its tangerine orchards and horse breeding due to the fact that the land cannot support rice farming due to the nature of the soil. The weather of Jeju Island depicts a vertical distribution from subtropics to a subarctic zone by its geographical position, its elevation, and topography. Owing to these environmental factors, the vegetation of Hallasan National Park is variously distributed from low-lying warm temperature forests to alpine or arctic forests of its highlands. It has a subtropical evergreen broad-leaved forest zone $600 \mathrm{~m}$ above sea level. Also, it has a temperate deciduous broad-leaved forest zone between 600 1,400 m above sea level. And it comprises the vegetation girdle of the subarctic zone or subalpine belt which is between 1,400 1,950 m above sea level. The endemic plants and the diversity of its species are abundant compared to other areas of the Korean Peninsula.

The floral investigation of Hallasan National Park began by Nakai [1], who reported 1,433 species, with both Lee [2] and Park et al. [3] examining the same area. The latest flora count reported 1,800 species by Kim [4] to 1,990 species by Kim et al. [5] in 2006.

The investigation of its medicinal plants began first with 405 species by Do et al. [6]. In 1968, 494 species were found by Do [7], and 425 species were reported by Yuk [8], and in 2004, 801 species were reported by Kim [9]. However, an ethnopharmacological study using orally transmitted traditional knowledge had yet to be considered.

Up to the present, although ethnopharmacological studies on islands of the world has widely been accomplished, such as the Reunion Island [10] of France, three islands on Vanuatu [11], and the Hainan Island of China [12], this research was the first of its kind in Korea and on Jeju Island.
This study aims to record traditional knowledge about medicinal plants orally transmitted from generation to generation in Jeju Island of Korea, where traditional culture and a biogeographic ecosystem, fortunately, have been relatively well conserved.

\section{Study area and investigative method Study area}

The study area is the largest volcanic island in Korea, which lies between $33^{\circ} 06^{\prime} \mathrm{N}$ to $34^{\circ} 00^{\prime} \mathrm{N}$ latitude and $126^{\circ} 08^{\prime} \mathrm{E}$ to $126^{\circ} 58^{\prime} \mathrm{E}$ longitude (Figure 1). The entire shape of the island is close to an oval formation in that the major axis inclines at about 15 degrees against the latitude from the northeast to the southwest and it is 2.4 times longer than the minor axis. Its length is $73 \mathrm{~km}$ and the width is $41 \mathrm{~km}$. The annual average temperature is $15.3^{\circ} \mathrm{C}$ and the annual precipitation is approximately $1,500 \sim 1,600 \mathrm{~mm}$. The study area is divided into two cities, which includes seven counties, five subcounties, and thirty-one villages in its administrative district and measures $1,849.18 \mathrm{~km}^{2}$ in area [13]. The total population in 2011 was 583,284 [13].

\section{Investigative method}

Field investigations were conducted throughout 27 sites starting from April, 2011 to November, 2011 (Figure 1). We interviewed 117 key informants who had lived over 40 years in the study area. Proper data was collected using the participatory rural appraisal (PRA) method, as the informants also became investigators themselves, participating in interviews, informal meetings, open and group discussions, and overt observations with semi-structured questionnaires [14-16]. The content of the semi-structured questionnaires was composed of diverse ethnopharmacological information, including local names, plant-parts used, ailments, methods of preparation, manufacturing and administration, dosage, and usable duration regarding each medicine [14-17].

All plant specimens were collected during their flowering or fruiting seasons, and were organized utilizing the normal specimen manufacturing method [14,17]. The voucher specimens were deposited for preservation in the herbarium of Jeonju University. The precise identification of plants mentioned by the informants was performed in accordance with Lee [18] and Lee [19]. Scientific names of plants were confirmed by the National Knowledge and Information System for Biological Species [20] of Korea.

\section{Quantitative analysis}

The informant consensus factor (ICF) was used to identify the ethnopharmacological importance of the collected plant species and to analyze the agreement degree of the informants' knowledge about each category of 


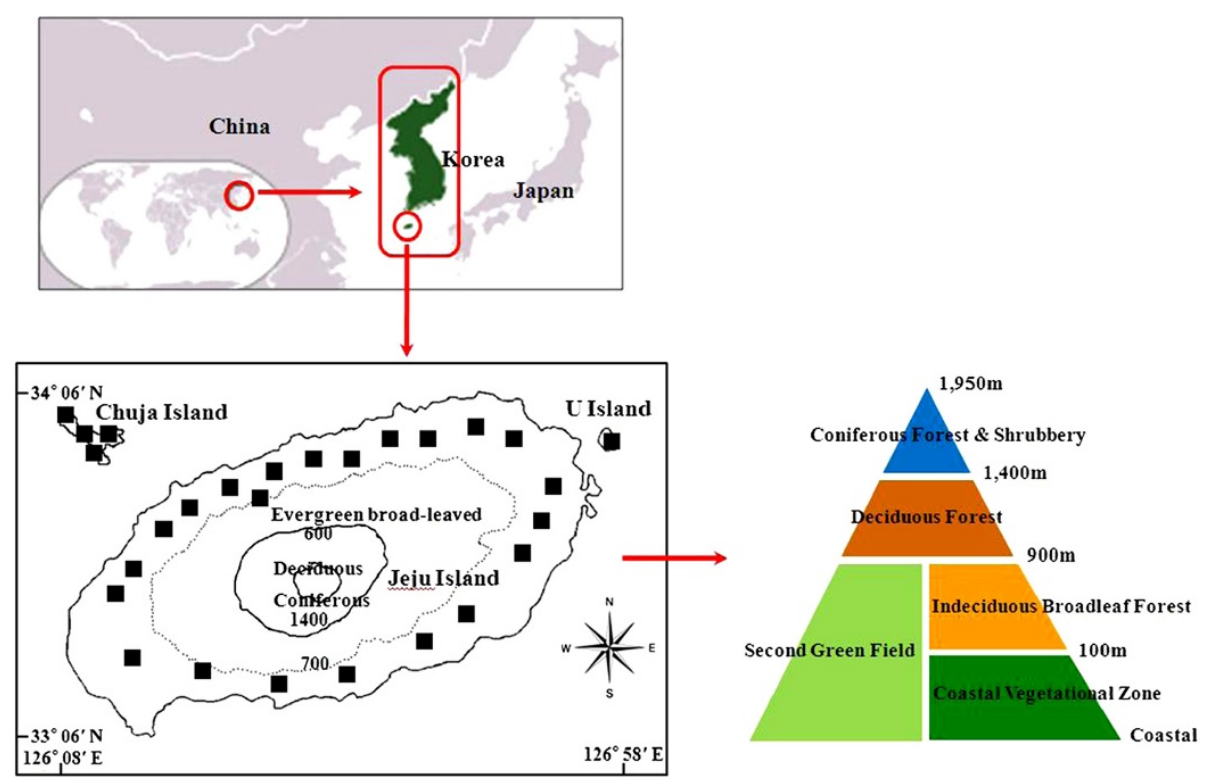

Figure 1 Investigation sites.

ailments [12,21,22]. The ICF was calculated using the following formula: $I C F=\left(n_{u r}-n_{t}\right) /\left(n_{u r}-1\right)$, where $n_{u r}$ is the number of times an ailment was mentioned in each category and $n_{t}$ is the number of plant species used.

The fidelity level (FL) was employed to determine the most important plant species used for treating certain diseases by the local herbal practitioners and elderly people living in the study area [14-16,23]. The FL was calculated using the following formula: $F L(\%)=N_{p} \times 100 / N$, where $N_{p}$ is the number of informants that mentioned the specific plant species used to treat certain ailments, and $N$ is the total number of the informants who utilized the plants as medicine for treating any given ailment.

\section{Results and discussion}

Demographic characteristics of participants in the study

All 117 informants (42 men and 75 women) were randomly selected at the community halls, the senior welfare centers, and the traditional markets at 27 designated sites. The average age of the informants was 78 years old with informants ranging in age from 40 to 94 . The elderly in their seventies and eighties occupied $82.9 \%$ of the total, while 91 informants never received any school education (Table 1).

\section{Medicinal plants and associated knowledge}

In this study, a total of 68 families, 141 genera, and 171 species of plants that showed 777 ways of usage were recorded from Hallasan National Park (Additional file 1: Table S1). The recorded plant species totaled $8.6 \%$ of the 1,990 species [5] and $21.3 \%$ of the 801 medicinal species [9] in the study area. The varying percentage exists for two reasons. One, the local community had not gathered wild plants for usage any longer. Two, most of the elderly people who directly gathered the medicinal plants, had forgotten their preparatory methods and usages. However, the 171 recorded plant species on Jeju Island exceeded the number per square kilometer found on the islands of other countries researched: 75 species found on Reunion Island in France, which is 1.3 times larger in area than Jeju Island [10], 133 species found on the three islands in Vanuatu, which is 6.7 times larger than Jeju

\section{Table 1 Demographic characteristics}

\begin{tabular}{lc}
\hline Gender & \\
Male & $42(35.9 \%)$ \\
Female & $75(64.1 \%)$ \\
Age & \\
$40-49$ & $2(1.7 \%)$ \\
$50-59$ & $1(0.9 \%)$ \\
$60-69$ & $10(8.5 \%)$ \\
$70-79$ & $49(41.9 \%)$ \\
$80-89$ & $48(41.0 \%)$ \\
$90-99$ & $7(6.0 \%)$ \\
Educational attainment & \\
Never attended school & $91(77.8 \%)$ \\
Attended school for less than 6 years & $6(5.1 \%)$ \\
Attended school for 6 years & $7(6.0 \%)$ \\
Finished middle school & $7(6.0 \%)$ \\
Finished high school & $6(5.1 \%)$ \\
\hline
\end{tabular}


Island [11], and 385 species collected on Hainan Island in China, which is 20 times larger than Jeju Island [12].

Looking into the distribution of the families, 14 species of Asteraceae occupied $11.1 \%$ of the total followed by 13 species of Rosaceae, 10 species of Rutaceae, and 9 species of Apiaceae, which occupied 5.0\%, 7.1\% and 3.0\% of the whole, respectively (Figure 2). Our analysis reveals that overall, 32 kinds of plant-parts were selected as medicinal materials. Roots were the most frequently used plant-parts, constituting $23.7 \%$ of the whole followed by fruits $(18.7 \%)$, leaves $(11 \%)$, seeds $(8.0 \%)$, whole plants (7.8\%), stems $(6.7 \%)$, aerial parts $(5.1 \%)$, and other sections of the plant (Figure 3). This data was similar to the investigative results of the western plains [16] and the southern mountainous regions [15] of Korea. These results were also similar to other countries including India [24-26], Spain [27] and Brazil [28].

The results depict 47 modes of preparation for the medicinal materials. Decoctions, pastes, macerations, brewings and infusions occupied 37.5\%, 14.1\%, 9.7\%, $4.9 \%$ and $4.8 \%$ of the whole, respectively. Oral administration accounted for $73.4 \%$ of the applications while topical application results were at $26.4 \%$, while nasal injection completed the list (Figure 4).

Considering the high frequency of medicinal plants mentioned more than 50 times related to medicinal efficacy by the key informants, Artemisia princeps Pamp. was used to treat 20 ailments, followed by Plantago asiatica L. for treating 16 ailments, Ulmus davidiana var. japonica (Rehder) Nakai for treating 13 ailments and Clematis terniflora var. mandshurica (Rupr.) Ohwi for treating 11 ailments (Figure 5). As the key informants continued to use these medicinal plants multiple times for specific ailments with favorable results, these species could be evaluated to possess the function of pharma-foods.

The fruit of Vitex rotundifolia L.f. was applied to the pillow for the cure of headaches. The fruit of Torreya nucifera (L.) Siebold \& Zucc. was used to cure vermicide, as in China and Japan [29-33]. Also, the whole plant of Phryma leptostachya var. oblongifolia (Koidz.) Honda was utilized as a bath supplement for skin ailments. These medicinal plant species should be developed as health products for their vital contribution in health care and health management.

Particularly, because Epimedium koreanum Nakai, which is used as a tonic in far eastern Asia [34], but is not grown in Hallasan National Park, Caulophyllum robustum Maxim., Thalictrum kemense var. hypoleucum (Siebold \& Zucc.) Kitag., and Cimicifuga biternata Miq. were taken as substitutes. However, the medicinal efficacies of these substitutes are very different from Epimedium koreanum Nakai [35]. We believe that the inhabitants of the island used these substitutes and obtained similar psychological benefits.

Finally, we have affirmed that the overall usage pattern of medicinal plants of the inhabitants on Jeju Island is nearly similar to both China and Japan due to the similarity of the flora of medicinal plants.

\section{Quantitative analysis \\ Informant consensus factor (ICF)}

The informant consensus factor (ICF) was used to identify the ethnopharmacological importance of the collected plant species $[21,22]$.

The category with the highest degree of consensus from informants was birth related disorders (0.92). The ranking followed with respiratory system disorders (0.90), skin

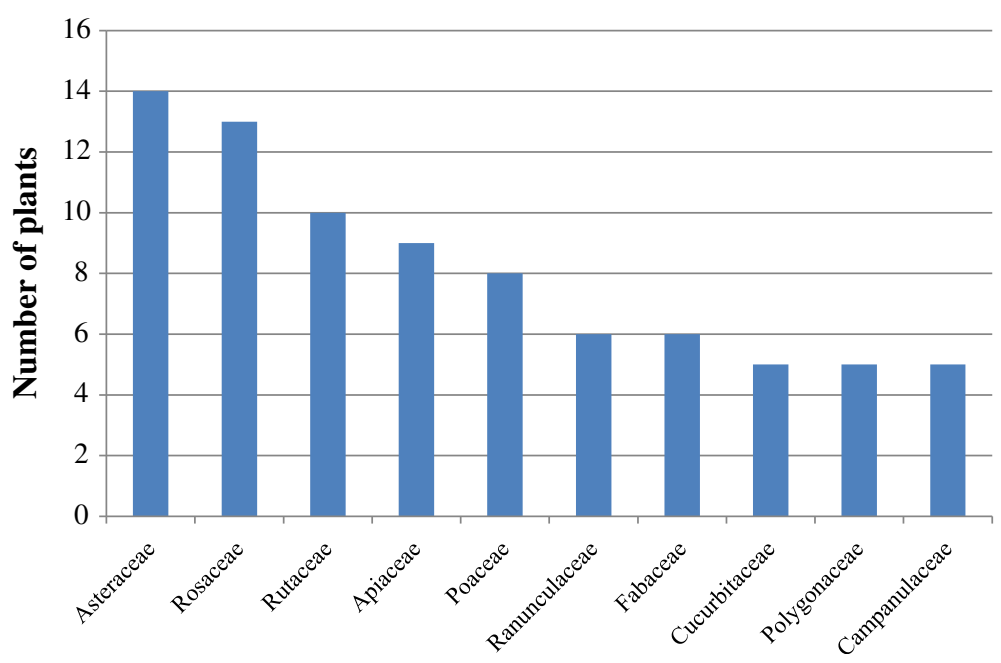

Figure 2 The most common plant families (56 Outliers omitted found in Additional file 1: Table S1). 


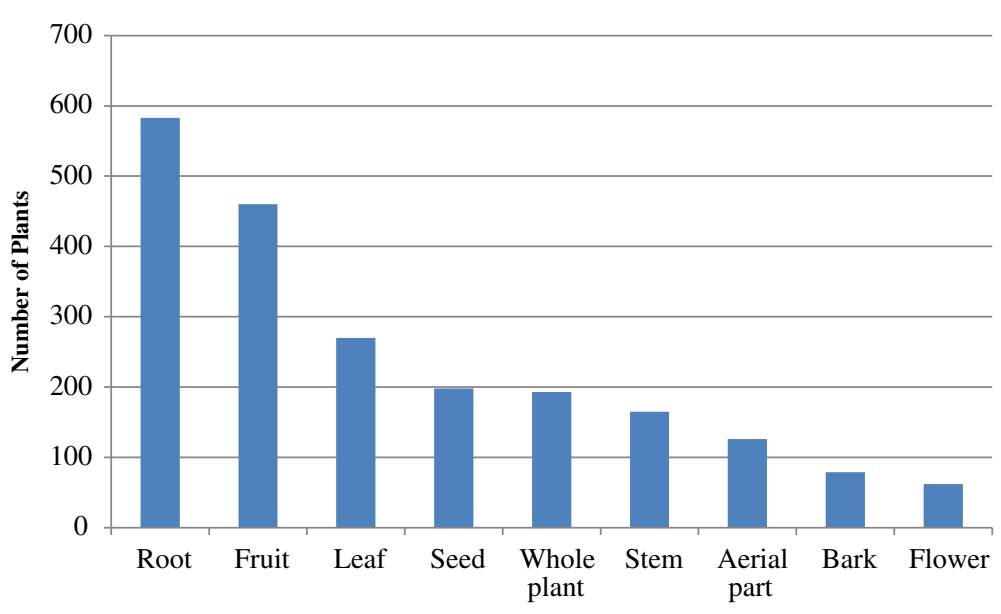

Figure 3 Used plant-parts of medicinal plants.

disease and disorders (0.89), genitourinary system disorders (0.87), physical pain (0.87), and other conditions. The lowest degree of consensus was diabetes (Table 2). These results reflect that in the past the hygienic, climatic and topographical environments of Hallasan National Park were at inferior levels. The high ICF value for respiratory system disorders was due to asthma resulting from an allergic reaction to monstrous mites found in many tangerine orchards [36]. Also, we can conclude that the lowest ICF value for diabetes is due to the coarse food eaten and the harsh living conditions on Jeju Island.

\section{Fidelity level (FL)}

The fidelity level is useful for identifying the inhabitants' most preferred species in use for treating certain ailments [23]. FL values in this study varied from $1.0 \%$ to $100 \%$. Generally, a FL of $100 \%$ for a specific plant indicates that all of the use-reports mentioned the same method for using the plant for treatment [37]. The study determined 36 species of plants with a FL of $100 \%$, even without considering plants that were mentioned only once for better accuracy (Additional file 1: Table S1). This information means that the informants had a tendency to rely on one specific plant species for treating one certain ailment than for several ailments.

With special attention given to important species $(\mathrm{N}$, $\mathrm{Np}$ ) of plants with an FL above 90\% regarding the viewpoint of the number of times mentioned and the consensus level for the specific ailment, Citrus tenuissima Tanaka. (81, 61), Pyrus pyrifolia Nakai $(41,34)$, Cimicifuga heracleifolia Kom.(14, 12) and Citrus aurantium L. (11, 11) were used to treat the common cold, respectively. Also, Cinnamomum camphora (L.) J. Presl $(53,48)$ was used for various cancers, Undaria pinnatifida (Harvey)

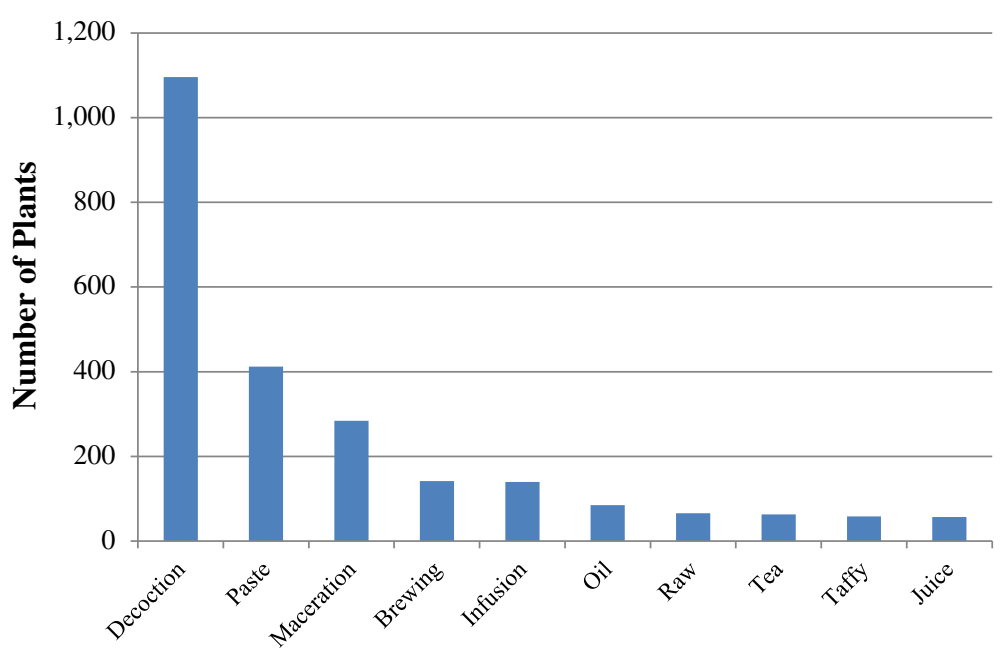

Figure 4 The most common preparation methods of medicinal plants (37 Outliers omitted found in Additional file 1: Table S1). 


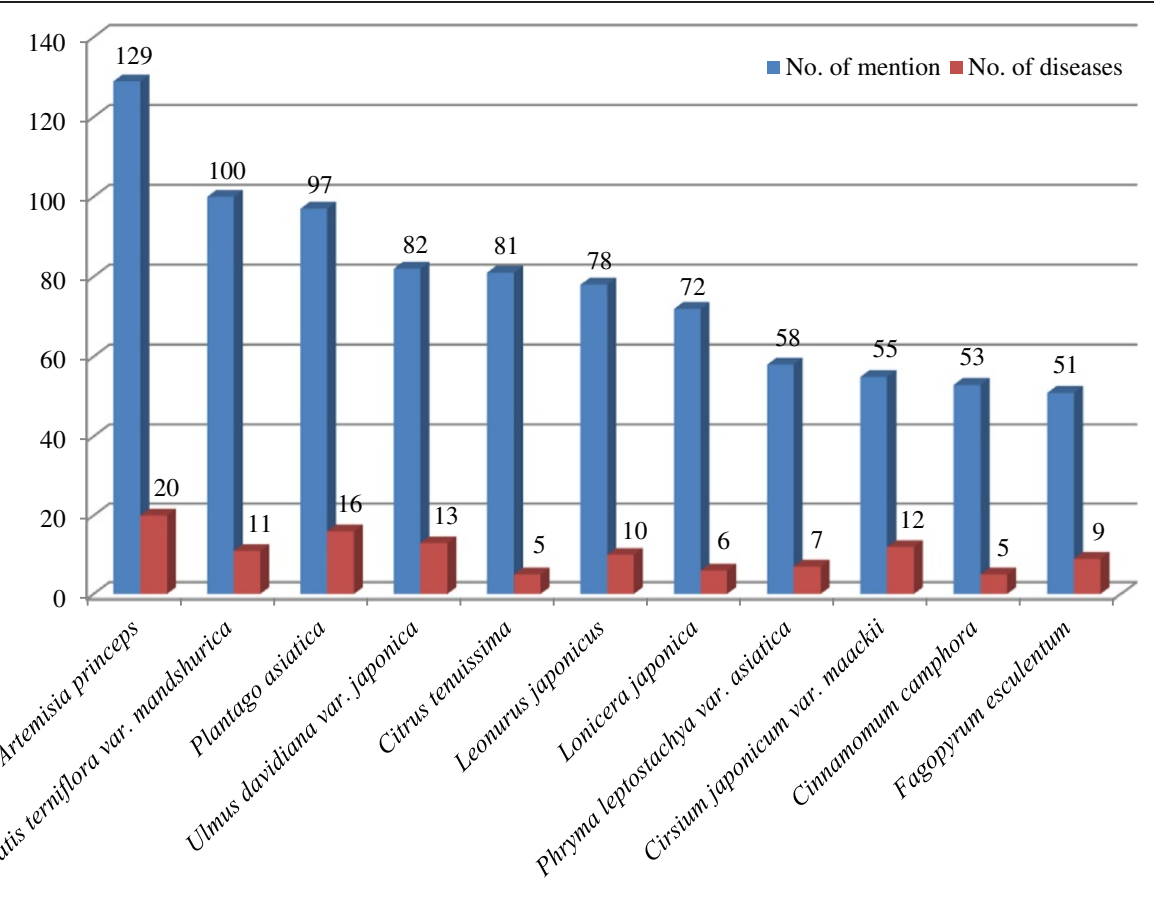

Figure 5 Ailment numbers and medicinal plants mentioned more than 50 times.

Suringar $(28,24)$ for Puerperalism, Torreya nucifera (L.) Siebold \& Zucc. $(18,18)$ for parasites, Solanum tuberosum L. (19, 17) for burns, Imperata cylindrica var. koenigii (Benth.) Druce $(18,16)$ for snakebites, Papaver somniferum L. $(15,12)$ for furuncle, and Potentilla chinensis Ser. var. chinensis $(11,11)$ for tingling (Additional file 1: Table S1).

Table 2 Category of ailments and their informant consensus factor (ICF) according to Heinrich et al. (1998)

\begin{tabular}{lccc}
\hline Symptom and ailment categories & TAXONS & Use citations & ICF \\
\hline Birth related disorders & 9 & 100 & 0.92 \\
Respiratory system disorders & 52 & 533 & 0.90 \\
Skin disease and disorders & 23 & 209 & 0.89 \\
Genitourinary system disorders & 25 & 189 & 0.87 \\
Physical pain & 51 & 376 & 0.87 \\
Cuts and wounds & 15 & 105 & 0.87 \\
Inflammation & 20 & 114 & 0.83 \\
Gastrointestinal disorders & 56 & 322 & 0.83 \\
Others & 45 & 226 & 0.80 \\
Poisonings & 11 & 52 & 0.80 \\
Nervous system disorders & 34 & 141 & 0.76 \\
Muscular-skeletal disorders & 16 & 48 & 0.68 \\
Circulatory system disorders & 32 & 97 & 0.68 \\
Liver complaints & 14 & 39 & 0.66 \\
Diabetes & 12 & 25 & 0.54 \\
\hline
\end{tabular}

\section{Review of local plant names}

The local plant names occasionally had information for understanding the properties of the medicinal plants. The pronunciation and meaning of dialectics, including the plant names of Hallasan National Park, were considerably different from standard Korean. The local plant names of Hallasan National Park were investigated by Nakai [1] and Kim [38]. The unique characteristics of the local plant names were also confirmed in this study. Namely, the phonemes of classic Korean in the 15th century have uniquely remained in the names of 25 plant species even to this day (Table 3 ).

\section{Conclusion}

Hallasan National Park has been designated as a cultural, topological, and natural heritage of the world by UNESCO, as it lies in the middle of the triangle which makes up the Korean Peninsula, the Japanese islands and the Chinese continent, and for being home to various plants which contain interesting properties according to an ethnopharmacological viewpoint.

Particularly, the characteristics of traditional ailments and the use of medicinal plants of Hallasan National Park have been brought to light. First, the traditional ailments of the local communities were evaluated by both climatic and geoecological environments. The respiratory ailments of Hallasan National Park were much higher than any other region because of windy and humid conditions. Second, ailments due to traditional occupations also existed, like cases of arthritis for the 
Table 3 Phonemes of classic Korean in the 15th century that uniquely remain in the names of 25 species

\begin{tabular}{|c|c|c|}
\hline Scientific name & Standard Korean name & Local name on Jeju Island \\
\hline Achyranthes japonica (Miq.) Nakai & Soemureup & 를마작쿨, 롤ㅁㅁ작쿨, 롤 믁작풀 \\
\hline Arisaema amurense for. serratum (Nakai) Kitag. & Cheonnamseong & 총남상 \\
\hline Breea segeta (Willd.) Kitam. f. segeta & Jobaengi & 흑 소왕이 \\
\hline Cirsium japonicum var. maackii (Maxim.) Matsum. & Eonggeongkwi & 촘소왕이, 촘소왕이, 촘소욍이 \\
\hline Citrus junos Siebold ex Tanaka & Yujanamu & 소유즌, 유즌낭 \\
\hline Citrus tenuissima Tanaka. & Dangyujanamu & 댕유증 \\
\hline Euonymus alatus (Thunb.) Siebold & Hwasalnamu & 촘빗낭 \\
\hline Euscaphis japonica (Thunb.) Kanitz & Malojumttae & 롤오동낭, 롤오름낭, 롤오좀낭, 롤오줌낭 \\
\hline Fagopyrum esculentum Moench & Memil & 모 롤 \\
\hline Gardenia jasminoides Ellis & Chijanamu & 치증낭 \\
\hline Lagenaria leucantha Rusby & Bak & 큭, 큭쭐, 클락, 클락쭐, 클악 \\
\hline Luffa cylindrica Roem. & Susemioi & 소가외, 스가웨 \\
\hline Melia azedarach L. & Meolguseulnamu & 롤구실낭, 롤코지낭, 롤쿠실낭, 몽쿠실낭 \\
\hline Polygonum aviculare L. & Madipul & 믁작쿨, 믐작풀 \\
\hline Poncirus trifoliata Raf. & Taengjanamu & 텡증낭, 탕쥐낭, 탕지낭 \\
\hline Prunus tomentosa Thunb. & Aengdonamu & 에영증낭 \\
\hline Raphanus sativus L. & $\mathrm{Mu}$ & 言비 \\
\hline Ricinus communis L. & Pimaja & 피만증 \\
\hline Schisandra chinensis (Turcz.) Baill. & Omija & 오미즌, 웨미증 \\
\hline Solanum nigrum L. var. nigrum & Kkamajung & 롤오좀 \\
\hline Sophora flavescens Solander ex Aiton & Gosam & 고좀, 너좀 \\
\hline Torreya nucifera (L.) Siebold \& Zucc. & Bijanamu & 비증남, 비종낭 \\
\hline Viola mandshurica W. Becker & Jebikkot & 롤고장, 롤싸움고장, 롤코장, 쓸궤풀 \\
\hline Zanthoxylum piperitum (L.) DC. & Chopinamu & 촘제피 \\
\hline Zanthoxylum planispinum Siebold \& Zucc. & Gaesancho & 는독낭 \\
\hline
\end{tabular}

women divers in Jeju Island. Third, people used medicinal plants of similar shape for the same purpose, even though they had a different efficacy (for example, Epimedium koreanum Nakai). These properties need further study using an investigative method in social medicine for a more exact analysis.

Also, medicinal plants, including Lagenaria leucantha Rusby, Citrus aurantium L., Trichosanthes kirilowii var. japonica Kitam., Neolitsea sericea (Blume) Koidz., Duchesnea indica (Andrews) Focke, and Phryma leptostachya var. oblongifolia (Koidz.) Honda were mentioned significantly and have high FL values in categories of a high ICF index. These species will be able to develop as pharmafoods or pharmaceuticals.

However, it is expected that the rapid decrease of the senior population which directly gathers wild medicinal plants will certainly lead to a greater loss of oral traditional knowledge similar to other regions in Korea $[15,16]$.

We keenly realize the necessity for a sustainable conservation of orally transmitted traditional knowledge of medicinal plants.

\section{Additional file}

Additional file 1: Table S1. Plant species used to treat ailments (Scientific names according to the international names index).

\section{Competing interests}

The authors declare that they have no competing interests.

\section{Authors' contribution}

HK and MJS complied the collected field data, analyzed and drafted the manuscript, $\mathrm{BH}, \mathrm{JWJ}$, and $\mathrm{SHL}$ revised the manuscript and added the valuable suggestions for improving the manuscript. All authors read and approved the final manuscript.

\section{Acknowledgements}

The authors are very grateful to all informants of the study area for sharing their oral traditional knowledge. This research was performed as a part of the Infrastructure Development Project for traditional knowledge-based Remedy (K11210) funded by the Acupuncture \& Moxibustion and Meridian Research Groups of the Korea Institute of Oriental Medicine.

\section{Author details}

${ }^{1}$ School of Alternative Medicine and Health Science, Jeonju University, 303 Cheonjam-ro, Wansan-gu, Jeonju 560-759, Republic of Korea. ${ }^{2}$ School of Liberal Arts, Jeonju University, 303 Cheonjam-ro, Wansan-gu, Jeonju 560-759, 
Republic of Korea. ${ }^{3}$ Korea Institute of Oriental Medicine, 1672 Yuseongdae-ro, Yuseong-gu, Deajeon 305-811, Republic of Korea.

Received: 22 February 2013 Accepted: 2 July 2013

Published: 9 July 2013

\section{References}

1. Nakai T: Flora of Quelpaert and Wando Island. Seoul: Govern. Chosen; 1914.

2. Lee DB: Flora of Cheju Island. Theses Coll Korea Univ (Coll Lib \& Arts) 1957, 2:339-412.

3. Park MK, Oh KC, Park BK, Lee YN, Lee EC, Yook CS: Plants of Hallasan Mountain. In Seoul: Report of the academic survey of Mt. Hanlasan and Is. Hongo : 1964:59-153.

4. Kim MH: Flora of vascular plant in Cheju-do. In Seoul: Report of the academic survey of Halasan (Mountain) natural preserve. 1985:246-298.

5. Kim CS, Koh JG, Song GP, Moon MO, Kim JE, Lee EJ, Hwang SI, Jeong JH: Distribution of naturalized plants in Jeju Island, Korea. Korean J Plant Res 2006, 19(5):640-648.

6. Do SH, Park DS, Yu SG: Investigation report of medicinal plants in Chejudo (1st Report). Sch Bull Coll Pharm Chung-Ang Univ 1960, 4:17-40.

7. Do SH: Investigation report of natural medicine resources in Cheju-do. Achiev Collect Herb Med Res Inst Seoul National Univ 1968, VI-VII:60-88.

8. Yuk CS: Resource plant for drug. In Seoul: Report of the academic survey of Mt. Hanlasan and Is. Hongo. Ministry of Culture, Sports and Tourism. 1968:146-153.

9. Kim HJ: Studies on the medicinal resource plants on Jeju Island, PhD thesis. Jeju: Jeju National University, Biology Department; 2004.

10. Poullain C, Girard-Valenciennes E, Smadja J: Plants from Reunion Island: Evaluation of their free radical scavenging and antioxidant activities. $J$ Ethnopharmacol 2004, 95:19-26.

11. Bradacs G, Heilmann J, Weckerle CS: Medicinal plant use in Vanuatu: A comparative ethnobotanical study of three islands. J Ethnopharmacol 2011, 137:434-448

12. Zheng $X$, Xing F: Ethnobotanical study on medicinal plants around Mt. Yinggeling, Hainan Island, China. J Ethnopharmacol 2009, 124:197-210.

13. Jeju Special Self-governing Province: The total population, administrative district, and area. http://english.jeju.go.kr/.

14. Kim H, Song MJ: Ethnobotany. In Seoul: World Science Com. 2008.

15. Kim H, Song MJ: Analysis and recordings of orally transmitted knowledge about medicinal plants in the southern mountainous region of Korea. J Ethnopharmacol 2011, 134:676-696.

16. Song MJ, Kim H: Ethnomedicinal application of plants in the western plain region of North Jeolla Province in Korea. J Ethnopharmacol 2011, 137:167-175.

17. Martin GJ: Ethnobotany: A people and plants conservation manual. London: Chapman \& Hall; 1995.

18. Lee TB: Illustrated flora of Korea. Seoul: Hyangmunsa; 1979.

19. Lee YN: Flora of Korea. Seoul: Kyohak Publishing Co; 2002.

20. National Knowledge and Information System for Biological Species (NKISBS): Scientific names of plants. http://www.nature.go.kr:9001/index.do

21. Heinrich M, Ankli A, Frei B, Weimann C, Sticher O: Medicinal plants in Mexico: healers' consensus and cultural importance. Soc Sci Med 1998, 47:1859-1871.

22. Heinrich M, Edwards S, Moerman DE, Leonti M: Ethnopharmacological field studies: a critical assessment of their conceptual basis and methods. J Ethnopharmacol 2009, 124:1-17.

23. Alexiades MN: Selected guidelines for ethnobotanical research: A field manual, Advances in Economic Botany, Volume 10. Bronx: The New York Botanical Garden; 1996

24. Sharma PK, Chahan NS, Lal B: Observations on the traditional phytotherapy among the inhabitants of Parvati Valley in western Himalaya, India. J Ethnopharmarcol 2004, 92:167-176.

25. Poonam K, Singh GS: Ethnobotanical study of medicinal plants used by the Taungya community in Terai Arc Landscape, India. J Ethnopharmacol 2009, 123:167-176.

26. Rajakumar N, Shivanna MB: Ethno-medicinal application of plants in the eastern region of Shimoga District, Karnataka, India. J Ethnopharmacol 2009, 126:64-73

27. Blanco E, Macia MJ, Morales R: Medicinal and veterinary plants of El Caurel (Galicia, northwest Spain). J Ethnopharmacol 1999, 65:113-124.
28. Coelho-Ferreira M: Medicinal knowledge and plant utilization in an Amazonian coastal community of Marudá, Pará State (Brazil). J Ethnopharmacol 2009, 126:159-175.

29. Hu Y, Hou TT, Zhang QY, Xin HL, Zheng HC, Qin LP, Rahman K: Evaluation of the estrogenic activity of the constituents in the fruits of Vitex rotundifolia L. for the potential treatment of premenstrual syndrome. J Pharm Pharmacol 2007, 59(9):1307-1312.

30. Hu Y, Hou TT, Xin HL, Zhang QY, Zheng HC, Rahman K, Qin LP: Estrogenlike activity of volatile components from Vitex rotundifolia L. Indian J Med Res 2007, 126(1):68-72.

31. Hu Y, Zhang Q, Xin H, Qin LP, Lu BR, Rahman K, Zheng H: Association between chemical and genetic variation of Vitex rotundifolia populations from different locations in China: its implication for quality control of medicinal plants. Biomed Chromatogr 2007, 21(9):967-975.

32. Kondo Y, Sugiyama K, Nozoe S: Studies on the constituents of Vitex rotundifolia L. fil. Chem Pharm Bull 1986, 34(11):4829-4832.

33. Watanabe K, Takada Y, Matsuo N, Nishimura H: Rotundial, a new natural mosquito repellent from the leaves of Vitex rotundifolia. Biosci Biotechnol Biochem 1995, 59(10):1979-1980.

34. Kim DS: Encyclopedia of Chinese herbal medicine. Seoul: Uiseongdang; 1994.

35. An SD, Jang BH, Lee MS, Kweon BS: Resource plants. Seoul: Sueonjinmunhwasa; 1996.

36. The Korean Academy of Asthma, Allergy and Clinical Immunology: Korean asthma management guidelines for adults. Seoul: National Strategic Coordinating Center for Clinical Research COPD; 2011.

37. Srithi K, Balslev H, Wangpakapattanawong P: Medicinal plant knowledge and its erosion among the Mien (Yao) in northern Thailand. J Ethnopharmarcol 2009, 123:335-342.

38. Kim MH: Investigation of the local names of trees in Cheju-do. J Korean Inst Landsc Architect 1977, 10:35-43.

doi:10.1186/1746-4269-9-48

Cite this article as: Song et al:: Ethnopharmacological survey of medicinal plants in Jeju Island, Korea. Journal of Ethnobiology and Ethnomedicine 2013 9:48.

\section{Submit your next manuscript to BioMed Central and take full advantage of:}

- Convenient online submission

- Thorough peer review

- No space constraints or color figure charges

- Immediate publication on acceptance

- Inclusion in PubMed, CAS, Scopus and Google Scholar

- Research which is freely available for redistribution 